Original Article

\title{
PHARMACISTS COMPLIANCE TO PRACTICE REGULATIONS AND GOOD PROFESSIONAL PRACTICE: A CASE STUDY OF NIGERIAN COMMUNITY PHARMACISTS
}

\author{
OBINNA ANYACHEBELU, DEBORAH ALUH* \\ Department of Clinical Pharmacy and Pharmacy Management, University of Nigeria Nsukka Enugu State Nigeria \\ Email: deborah.aluh@unn.edu.ng
}

Received: 11 Mar 2018 Revised and Accepted: 06 Jun 2018

\begin{abstract}
Objective: This study was designed to assess community pharmacists' compliance to rules and regulations guiding the practice of pharmacy in Anambra state, Nigeria.

Methods: The study was carried out using a mixed method. In the first phase, adapted and validated questionnaire was used to obtain demographic data and information on some practice standards. While in the second phase, the researcher interviewed the practicing pharmacists on some of the key practice standards followed by observation of the items included in the interview. Statistical analysis was computed using SPSS and minitab versions 23.0 and 14.0 respectively. Descriptive analysis was carried out on the demographic items and other sections of the questionnaire. Quantitative data were analysed by computing frequency tables. Average percentage score for each section of the questionnaire was calculated. One-way ANOVA [with post hoc test-LSD] and Independent-Samples T Test were used to examine significance relationship between demographic variables and the different dimensions of the questionnaire.
\end{abstract}

Results: The response rate to the study questionnaire was $82 \%$. While the questionnaire study had a mean good compliance level to environmental and dispensing practice standards, the interview and observation phase observed poor compliance to some items in this section. The study further observed good implementation level for pharmaceutical care, except for proper documentation. Although the pharmacists' knowledge of pharmacovigilance activities was observed to be fair, their involvement in the activity was poor.

Conclusion: The Overall findings of the study did not record an excellent compliance level to good professional practice by community pharmacists in Anambra state, Nigeria.

Keywords: Pharmacists, Nigeria, Pharmacy practice, Pharmacovigilance, Compliance, Regulations

(C) 2018 The Authors. Published by Innovare Academic Sciences Pvt Ltd. This is an open access article under the CC BY license (http://creativecommons.org/licenses/by/4.0/] DOI: http://dx.doi.org/10.22159/ijpps.2018v10i7.25858

\section{INTRODUCTION}

The services of pharmacists have continued to evolve from productoriented practice to patient-oriented practice over time, with a goal to achieve definite outcomes which can be economic, humanistic and clinical, viewing from different perspectives [1]. The increasing roles, especially in patient care, should be backed by law and ethics to achieve good professional practice like in other professions. Community Pharmacists as the most accessible healthcare professionals are expected to observe a high standard of practice as they have a great impact on community health [2-4]. This standard of practice should be observed in filling prescriptions, dispensing over the counter medications, giving proper counselling regarding drugs and in other public health activities.

Studies on Pharmacists' compliance to practice regulations have been carried out all over the world. Maria et al. reported that pharmacists in Moldova are deeply rooted in the traditional form of practice as they are not moving with the new trends of good pharmacy practice such as, pharmaceutical care and drug information [5]. A similar study in Iran by Hanafi et al. revealed a low level of good professional practice by community pharmacists with respect to dispensing activities and pharmaceutical care 6] Villako reported that in choosing a pharmacy, Estonian customers favoured location, proper professional outlook, privacy, discretion and confidentiality and expected help with choosing the right medicine, as well as professional consultation [7].

In Nigeria, little has been documented about compliance of community pharmacists to practice standards. The Pharmacists Council of Nigeria (PCN) established by the Federal government of Nigeria has been charged with the responsibility among others of regulating all premises where pharmaceutical activities are carried out including community pharmacies[6-10] Compliance to their rules is at the centre of good professional practice. It is established that there are standard practice guidelines for community pharmacists stipulated by the Pharmacists council of Nigeria. But the level of compliance to these guidelines has not been established. This survey seeks to assess the compliance level of community pharmacists to regulations set up by the regulatory body for pharmacy practice. It also aims to assess the professional outlook of the pharmacy premise, the legality of dispensing, involvement of the pharmacists in pharmaceutical care activities, knowledge and involvement in pharmacovigilance within the area of study. This study will provide a point of reference for the degree of involvement in good professional pharmacy practice by community pharmacists in Anambra state Nigeria and their compliance to practice standards, laws and ethics.

\section{MATERIALS AND METHODS}

\section{Study setting}

This study was conducted among the community pharmacists in Anambra state, Nigeria. The state has Awka as the state capital and other major cities including Onitsha, the commercial base of the state and Nnewi, the industrial hub of the state. The study was carried out in these cities being the places populated with community pharmacies. These pharmacies are open for sales and services for an average of $12 \mathrm{~h}$ every day.

\section{Study design}

The study was a cross-sectional study carried out amongst community pharmacists practising in registered retail community pharmacy outlets in Anambra state Nigeria. The required sample size of 109 pharmacists was calculated using Yamane sample size calculation technique [11]. However, to account for potential refusals and incorrect filling of some questionnaires, an additional percentage of the participating pharmacists were added bringing a total number of 140 community pharmacists. The 140 pharmacists were sampled using purposive sampling technique with inclusion criteria being pharmacists that have worked in a registered community pharmacy for at least 6 mo. 


\section{Survey instrument}

For the first phase of the study, a questionnaire adapted from a study in Moldova was used [5]. The questionnaire was subjected to face validation by five experts in the field. They included two lecturers from the Department of Clinical Pharmacy and Pharmacy Management, Nnamdi Azikiwe University Awka, the Director of Pharmaceutical Services [DPS] Anambra state, the Liaison officer, Pharmacists' Council of Nigeria [PCN] Anambra state and the Chairman Association of Community Pharmacists in Nigeria [ACPN], Anambra state chapter. The questionnaire contained 57 questions used in obtaining information on demography, environmental and managerial activities, dispensing activities, pharmaceutical care activities and pharmacovigilance activities.

A pilot study was then carried out on 20 randomly selected community pharmacists in a location different from the study site. Reliability test analysis [Cronbach's alpha analysis] was used to test for internal consistency and reliability of instrument. Results of the pilot study were used to further modify the questionnaires to improve on clarity and flow.

The proforma used for the second stage of the research was derived from the initial questionnaire. It had 18 questions drawn from all sections of the questionnaire that could easily be assessed.

\section{Data collection}

During the first phase of the study, the questionnaires were distributed to 140 pharmacists across the three cities in the state. The second phase of the study involved observation and pharmacist interview to assess some practice standards included in the questionnaire. On visiting some of the pharmacies, the researcher inquired for a pharmacist, whom he engaged in an interview and observatory session on some of the key practice and professional standards required of a community pharmacy/pharmacist.

\section{Data analysis}

Statistical analysis was carried out using SPSS versions 23.0 and minitab version 14.0 as computing tools. Descriptive analysis was carried out on the demographic items and other sections of the questionnaire, represented by frequency [percentage] or mean \pm standard deviation. Quantitative data were analysed by computing frequency tables, means and percentages. Questionnaire items were categorized into four dimensions: environmental and managerial; dispensing; pharmaceutical care; and pharmacovigilance activities. Scores were assigned to each item of the questionnaire [i.e. Yes $=1$ and No $=0$ ] to treat them as continuous data suited for quantitative analysis. Average percentage score for each dimension was calculated. Skewness and kurtosis of item-scale scores were assessed to determine how much their distribution varied from a normal distribution. One-way ANOVA [with post hoc test-LSD] and Independent-Samples $\mathrm{T}$ Test were used to examine significance relationship between demographic variables and the different dimensions of the questionnaire. Significant value of $p<0.05$ was employed. Data from observation and interview were also computed into frequency tables and percentages.

\section{Ethical considerations}

The study protocol was approved by the ethical committee of Chukwuemeka Odumegwu Ojukwu University Teaching Hospital (COOUTH), Amaku, Awka. The ethical clearance had the approval number-COOUTH/AA/VOI. X1/040. A consent statement was included at the beginning of the questionnaire for the community pharmacists. Anonymity of respondents was maintained as names weren't mentioned or documented.

\section{RESULTS}

A total number of 115 questionnaires were returned out of 140 distributed, giving a response rate of $82 \%$. The demographic distribution of the respondents (table 1), indicate that almost half [47\%] of the respondents were less than $30 \mathrm{y}$ of age with a male to female ratio of 1:3. Majority of the respondents had B. Pharm as their highest degree with only $11.3 \%$ having a postgraduate degree (Masters in Pharmacy), almost two-thirds of the surveyed pharmacists [69.6\%] indicated that they have practiced for about 5 $\mathrm{y}$ or less at an average of $3 \mathrm{~h}$ per day while $16.5 \%$ had worked for between 6 and $10 \mathrm{y}$ at an average of $8 \mathrm{~h}$ every day.

Table 1: Demographic characteristic of responding community pharmacists [n=115]

\begin{tabular}{ll}
\hline Variable & Response N [\%] \\
\hline Age & $54[47]$ \\
$\leq 30$ & $20[17.4]$ \\
$31-40$ & $26[22.6]$ \\
$41-50$ & $15[13]$ \\
$\geq 51$ & $66[57.4]$ \\
Gender & $49[42.6]$ \\
Male & \\
Female & $80[69.6]$ \\
Year[s] of experience & $19[16.5]$ \\
65 & $16[13.9]$ \\
-10 & \\
Average working hours in the pharmacy & $43[37.4]$ \\
3 & $63[54.8]$ \\
8 & $9[7.8]$ \\
Highest degree obtained & $102[88.7]$ \\
B Pharm & $13[11.3]$ \\
M. Pharm & \\
\hline
\end{tabular}

\section{Environmental and managerial activities}

The surveyed community pharmacists' compliance to environmental and managerial activities indicated a good level of compliance with a mean score of $80.3 \% \pm 13.3$. Responses to the individual items in the section showed that about half of the respondents (51.3\%) claimed to have a superintendent pharmacist at all times. Almost all the respondents $(97.4 \%)$ claimed to possess a patient counselling area, with suitable barriers and were comfortable enough for patient relaxation and easy disclosure of information. Majority of the respondents (91.3\%) claimed that a poison book and cupboard were available in the pharmacy and that the pharmacies possess relevant reference books. Ensuring proper professional dressing of staff, training of staff to fulfil their roles and stocking of quality drugs were other items with high response rate. These are shown in table 2. Further analysis revealed that there was no significant relationship between the responses and demographic variables as shown in table 3. 
Table 2: Responses to environmental and managerial activities

\begin{tabular}{ll}
\hline Item & Response yes N (\%) \\
\hline Presence of superintendent pharmacist & $59(51.3)$ \\
Visibility of original professional license of the pharmacist & $51(44.3)$ \\
Presence of counselling area & $112(97.4)$ \\
Privacy and seclusion of counselling area & $107(93)$ \\
The comfort of counselling area & $106(92.2)$ \\
Patient counselling area solely used for the designated activity & $66(57.4)$ \\
Appropriate storage condition for medicines & $113(98.3)$ \\
Availability of refrigerator/cold chain for wet drug storage & $111(96.5)$ \\
Medications as sole items stored in the refrigerator & $60(52.2)$ \\
Availability of appropriate poison cupboard for controlled drugs & $105(91.3)$ \\
Availability of poison book & $105(91.3)$ \\
Adequacy of staff number in place to safely and effectively carry out activities & $90(78.3)$ \\
The appropriate professional dressing of staff working in the pharmacy & $104(90.4)$ \\
Trained and competent staff available & $81(70.4)$ \\
Training for newly employed staff & $112(97.4)$ \\
\hline
\end{tabular}

Table 3: Effect of demography on environmental and managerial activities

\begin{tabular}{|c|c|c|}
\hline Variable & Mean[\%] \pm SD & P-value \\
\hline \multicolumn{3}{|l|}{ Age } \\
\hline$<30 y$ & $78.5 \pm 11.6$ & 0.198 \\
\hline $31-40 y$ & $78.1 \pm 10.6$ & \\
\hline $41-50 y$ & $79.8 \pm 12.3$ & \\
\hline $51-60 y$ & $77.5 \pm 14.3$ & \\
\hline \multicolumn{3}{|l|}{ Gender } \\
\hline Male & $78.5 \pm 13.7$ & 0.082 \\
\hline Female & $82.9 \pm 12.5$ & \\
\hline \multicolumn{3}{|l|}{ Years of experience } \\
\hline$\leq$ 5years & $79.9 \pm 13.7$ & 0.602 \\
\hline >5years & $81.3 \pm 12.6$ & \\
\hline \multicolumn{3}{|l|}{ Highest degree } \\
\hline Graduate degree & $79.8 \pm 13.6$ & 0.222 \\
\hline Postgraduate degree & $84.6 \pm 10.3$ & \\
\hline
\end{tabular}

\section{Dispensing activities}

Respondents showed a good level of compliance to dispensing regulations with a mean score of $76.4 \% \pm 14.4$ table 4 shows descriptive analysis of individual items for dispensing section. Majority of the respondents $(98.3 \%)$ revealed that they counsel and provide drug-related information to patients before handing out medications, even in cases of refill irrespective of whether the patient already has the needed information. However, a significant proportion $(84.3 \%)$ revealed that in a situation whereby the patient refuses to be counselled, they still dispense the medications. Most of the community pharmacists (83.5\%) agreed that on some occasions, they dispense prescription only medications without valid prescriptions while almost all $(94.8 \%)$ revealed that they visit reference materials available to them to evaluate prescriptions. Further analysis did not find a significant relationship between the responses and demographic variables (table 5).

Table 4: Responses to dispensing activities [n=115]

\begin{tabular}{ll}
\hline Item & Response yes N (\%) \\
\hline Pharmacist in charge of all medication dispensing & $45(39.1)$ \\
Consideration for the duration of time to take an OTC before consulting a doctor if symptoms & $87(75.7)$ \\
persist & $60(52.2)$ \\
All prescriptions going through a pharmacist & $82(71.3)$ \\
Assessment of prescription legality & $110(95.7)$ \\
Assessment of prescription appropriateness for patient & $113(98.3)$ \\
Patient counselling before drug dispensing & $96(83.5)$ \\
Dispensing of POM without prescription & $81(70.4)$ \\
Recording of poisons in poison book & $109(94.8)$ \\
Evaluate prescriptions using reference materials & $97(84.3)$ \\
Dispense medication upon patient refusal for counselling & $105(91.3)$ \\
Patient counselling in prescription refill cases & $53(46.1)$ \\
Administration of injections & $69(60.0)$ \\
Provision of first aid services & $71(61.7)$ \\
Appropriate disposal of expired medications & $56(48.7)$ \\
Carry out any form of diagnostic tests & \\
\hline
\end{tabular}


Table 5: Effect of demography on dispensing activities

\begin{tabular}{|c|c|c|}
\hline Variable & Mean (\%) \pm SD & P-value \\
\hline \multicolumn{3}{|l|}{ Age } \\
\hline$<30 y$ & $58.3 \pm 18.8$ & 0.352 \\
\hline $31-40 y$ & $52.5 \pm 11.2$ & \\
\hline $41-50 y$ & $48.1 \pm 22.3$ & \\
\hline $51-60 y$ & $53.3 \pm 22.9$ & \\
\hline \multicolumn{3}{|l|}{ Gender } \\
\hline Male & $74.5 \pm 15.9$ & 0.098 \\
\hline Female & $78.9 \pm 11.5$ & \\
\hline \multicolumn{3}{|l|}{ Years of experience } \\
\hline$\leq$ 5years & $76.6 \pm 13.8$ & 0.782 \\
\hline$>$ 5years & $75.8 \pm 15.8$ & \\
\hline \multicolumn{3}{|l|}{ Highest degree } \\
\hline Graduate degree & $75.6 \pm 14.4$ & 0.119 \\
\hline Postgraduate degree & $82.2 \pm 12.7$ & \\
\hline
\end{tabular}

\section{Pharmaceutical care activities}

With a mean percentage score of $78.6 \% \pm 11.9$, the responding community pharmacists showed a good level of involvement in pharmaceutical care activities. Individual item responses represented in table 6 shows that all the pharmacists claimed to establish responsible professional relationships with their patients. Almost all the respondents $(99.1 \%, 98.3 \%$ and $95.7 \%$ respectively) claimed to inquire about patients past medical/medication history, assess patients health related problems with their medication requirements and take into consideration, consumption of herbal products. Many of the pharmacists said they carry out health screening activities like blood pressure measurement (93.9\%), body weight measurement (93.9\%). However, few of them they measure blood sugar (49.6\%) and cholesterol level $(2.6 \%)$ as a form of health promotion. Demographic factors did not affect the responses significantly.

Table 6: Responses to pharmaceutical care activities [ $n=115]$

\begin{tabular}{ll}
\hline Item & Responses yes N (\%) \\
\hline Establishment of responsible professional relationships with patients & $115(100)$ \\
Inquiry into patients past medical history and past or present medication status & $114(99.1)$ \\
Assessment of patients' health-related problems and medication requirements & $113(98.3)$ \\
Consideration of herbal products/complementary & $110(95.7)$ \\
medicine consumption & $96(83.5)$ \\
Consultation with other pharmacists about specific patient problems & $57(49.6)$ \\
Establishment of the professional relationship with physicians to enable joint & $29(25.2)$ \\
management & $108(93.9)$ \\
Documentation of patient specific problems and medications & $57(49.6)$ \\
Blood pressure measurement & $108(93.9)$ \\
Blood sugar measurement & $3(2.6)$ \\
Measurement of body weight & \\
\hline
\end{tabular}

Table 7: Responses from observation/interview at community pharmacies [n=85]

\begin{tabular}{ll}
\hline Item & Response yes N (\%) \\
\hline Presence of pharmacist & $46(54.1)$ \\
Visibility of pharmacists license & $3(3.5)$ \\
Counselling area present & $79(92.9)$ \\
Availability of refrigerator/cold chain & $80(94.1)$ \\
Availability of poison cupboard for controlled drugs & $29(34.1)$ \\
Appropriate professional dressing of staff & $26(30.6)$ \\
Prescriptions going through a pharmacist & $27(31.8)$ \\
Counselling or provision drug-related information to patients prior to dispensing & $83(97.6)$ \\
Dispensing prescription only medications without a valid prescription & $85(100)$ \\
Recording of poisons in the poison book & $15(17.6 \%)$ \\
Dispensing of medication even with patient refusal for counselling & $85(100)$ \\
Administration of injections & $34(40)$ \\
Inquiry into patients past medical history and past or present medication status & $80(94.1)$ \\
Blood pressure measurement & $83(97.6 \%)$ \\
Blood sugar measurement & $65(76.5 \%)$ \\
Measurement of body weight & $83(97.6 \%)$ \\
Cholesterol testing & $2(2.4 \%)$ \\
Documentation of patient specific problems and pharmaceutical care activities & $2(2.4)$ \\
Documentation/reporting of adverse drug reactions & $0(0)$ \\
\hline
\end{tabular}

\section{Pharmacovigilance activities}

The surveyed pharmacists knowledge and involvement in pharmacovigilance recorded a fair result, with a mean score of $54.3 \% \pm 19.4$ Descriptive analysis of individual items in this section revealed that almost all (93\%) the respondents were knowledgeable about the National reporting form (NAFDAC yellow form) used in reporting adverse drug reactions. Less than a quarter of the respondents $(15.7 \%)$ claimed to report adverse drug reactions in their facilities. Majority of the community pharmacists (95.7\%) were 
of the opinion that trivial ADRs that resolve quickly, already known ADRs associated with certain drugs and ADRs associated with herbal medications should be reported while $3.5 \%$ of them agreed that ADRs that do not cause harm to patients should also be reported. There was also no significant relationship between the outcomes and demographic variables.

\section{Observation/Interview}

Descriptive analysis shows that among the community pharmacies visited for interview/observation, almost half (54.1\%) had pharmacists present at the time of visit while, while just 3.5\% of the pharmacies had professional licenses of the superintendent pharmacists visible. Observations revealed that private patient counselling areas were present in the majority $(92.9 \%)$ of the pharmacies while only $30.6 \%$ of pharmacies had professionally dressed staff. Refrigerators were also sighted in the majority (94.1\%) of the pharmacies. Almost all the pharmacies visited were willing to dispense prescription-only medicines without a legally signed prescription and rarely filled poisons dispensed in a poison book.

Interview responses indicated that, in many of the pharmacies (68.2\%), prescription were handled by people other than pharmacists and majority of the community pharmacists (97.6\%) counsel patients about medications dispensed. However, in cases whereby the patients refused to be counselled, the respondents still went ahead to dispense medications. Some of the pharmacists (40\%) revealed that injections were administered within the pharmacy, while the majority of the respondents $(97.6 \%$ and $76.5 \%$ respectively) carried out blood pressure measurement and body weight measurement. The respondents surveyed did not document pharmaceutical care activities carried out neither did they document adverse drug reactions.

\section{DISCUSSION}

The result of this study revealed a satisfactory level of community pharmacists' compliance to environmental, dispensing and pharmaceutical care practice standards while pharmacovigilance activities recorded a fair result. The study indicated the varying degree of compliance to individual practice standards, sectionalized into environmental, dispensing, pharmaceutical care and pharmacovigilance activities.

One of the minimum legislative requirements or practice standards for pharmacists according to Puspitasari et al. is the provision of drug information to consumers especially patients with prescription and health challenge [12]. This information must be provided in a secluded area to ensure confidentiality and boost patient confidence in the community pharmacist. The presence of these counselling areas in the majority of the pharmacies indicates that community pharmacists have strong positive beliefs about patient counselling [13] in the course of practice and shows a high compliance level to the presence of counselling area as a key practice standard. The respondents surveyed claimed that the counselling areas were comfortable enough for patient relaxation and easy disclosure of information. This was not the case during observation, as these counselling rooms were observed to be small, used for other purposes asides counselling and uncomfortable for consultations in most premises.

Majority of the community pharmacists who took part in the study reported that they counsel and provide drug-related information to patients before handing out medications. This they did even in cases of refill, not minding whether the patient already has the needed information. The importance of this is embedded in a study stating that pharmacist medication review, patient counselling, and telephone follow-up were associated with a lower rate of preventable ADEs [14]. But then, some of the respondents revealed that in a situation whereby the patient refuses to be counselled, they still go ahead to dispense the medications.

Although counselling areas were present, and pharmacists claimed to be involved in counselling, the duration of consulting time recorded according to their responses reveal that little time is spent discussing with patients. This concurs with findings from a study by
Kirking where he reported that when the service is provided by pharmacists, counselling sessions are usually brief, pharmacistinitiated, and one-way conversations to the patient [13]. The possible causes could be the small size of counselling rooms, use of counselling rooms as sub store, uncomfortable rooms, negligence, rush to attend to as many patients as possible and inadequate staff strength. These findings can also be likened to suggestions of Azhar, that community pharmacies have been able to improve access to medicines by just providing medicines to the masses but rendered limited services in terms of counselling [15].

Other claims made by the respondents include; possession of a poison book and cupboard in the pharmacy, the professional setting of pharmacy, professional dressing of staff, and training of staff to fulfil their roles. However, observation and interview carried out revealed some discrepancies in their claims meaning that during the survey, participants made some false claims in the questionnaire that were noticed on observation and interaction. Studies have reported similar inconsistencies between the self-reported behaviour of pharmacists and their actual practice measured [16]. It is possible that pharmacists provide more socially desirable responses in the questionnaires [17].

Majority of the respondents reported that they possessed relevant reference books such as the British national formulary which they visit to evaluate the appropriateness of prescriptions in different cases. These reference materials in addition to periodicals and the unending knowledge available on the internet are necessary in present times. Because, as the world of medicine continues to grow continuous update and evaluation is needed to assess drug interactions, adverse drug reactions and also bring about costeffective therapy [18].

Some of the dispensing malpractices seen in developing countries are attributed to the low level of adherence to the existing laws and regulations on good dispensing practice, lack of knowledge and professionalism among pharmacists, demand from consumers, and business orientation of pharmacies [19]. Nigeria is not left out as this study revealed that $85 \%$ of the community pharmacists surveyed dispensed prescription only medications without valid prescriptions as opposed to demanding for the prescription order as required law before dispensing such medications.

Pharmaceutical care is a mainstay in pharmacy practice and the respondents in this study were assessed on their level of involvement. All the community pharmacists surveyed claimed to establish responsible professional relationships with their patient which is the foundation for proper pharmaceutical care practice. Almost all respondents claimed to inquire about patients past medical/medication history, assess patients health related problems with their medication requirements and take into consideration, consumption of herbal products. In addition, many of the pharmacists said they carried out health screening activities like blood pressure measurement, body weight measurement while only a few revealed that they measure blood sugar and cholesterol level. This is a way of gathering subjective and objective data which can be used for assessment of patients' healthcare needs and initiating an individualized care plan to achieve definite outcomes.

These findings are plausible as Erah and Nwazuoke, had earlier reported some elements of pharmaceutical care activities such as medication history taking, blood pressure measurement and a few others in Benin City, Nigeria [20]. Moreover, a study by Oparah and Eferakeya which assessed the attitudes of 1005 pharmacists in Nigeria towards pharmaceutical care revealed that that their attitudes and willingness towards implementing pharmaceutical care were favourably high irrespective of the practice settings and possible barriers [21].

Majority of the community pharmacists surveyed did not document pharmaceutical care activities carried out thereby providing no evidence or source of reference for provided care. The importance of documenting patient specific information cannot be overemphasized as it helps for follow up and monitoring. As much as documentation is important it's also important to record important information. Thus, the saying that a pharmacist recording every activity is not required; the extent of documentation will vary depending on the 
situation [22]. It should be carried out in such a way that any person other than the provider should be able to decipher what has been done [23].

Pharmacovigilance has been defined by the World Health Organisation as the science and activities relating to the detection, assessment, understanding and prevention of adverse effects or any other drugrelated problem $[24,25]$. Majority of respondents revealed that they are knowledgeable about the National reporting form used in Nigeria for reporting adverse drug reactions and also, gave good responses on adverse drug reactions they think should be reported. But less than a quarter of the respondents claimed to report adverse drug reactions in their facilities. This corroborates the findings of Anne et al., in Norway that the pharmacists had positive attitudes towards pharmacovigilance, but very little experience with reporting [26]. However, Salim et al., [ reported that majority of the pharmacies do not have ADR reporting form and only a few established the forms in their premise in India [27]. This is similar to the findings of a study by Mahmoud et al., in Saudi Arabia, where the majority of community pharmacists in Riyadh had poor knowledge of the ADR reporting process [28]. Studies have disclosed that great numbers of pharmacists are ignorant of how to obtain ADR Forms in Bangalore [29]. This suggests that pharmacovigilance authorities should take necessary steps to urgently design interventional programs in order to increase the knowledge and awareness of pharmacists regarding the ADR reporting process. An effective implementation of ADR monitoring would result in better and safe use of these drugs which would ultimately result in better patient care [30].

A major limitation of the study is the relatively small sample size which affects the generalizability of the result. However, Anambra state is made of a different cadre of pharmacies quite representative of community pharmacy practice in other parts of the country and can also serve as a pilot for further studies. The inclusion of Intern Pharmacists under training who might not have total knowledge of practice standards and ethics. However, practice duration of at least 6 mo was used as a benchmark.

\section{CONCLUSION}

The community pharmacists surveyed had a good knowledge of proper professional practice activities and regulation, however, this knowledge was generally not translated into practice. This calls for proper enlightenment and enforcement of rules and regulations to improve pharmacy practice within Nigeria and beyond. Studies should be carried out in other locations to ascertain uniformity of problem; more studies should also be carried out to ascertain the determinants of these loopholes in pharmacy practice. Focus group discussions should be organized between key players in the industry including the law enforcing body, Pharmacists' Council of Nigeria and also the body of community pharmacists to dialogue and proffer lasting solutions together with massive sensitization on the harms associated with wrongful practice and the gains associated with the proper professional practice.

\section{AUTHORS CONTRIBUTIONS}

Anyachebelu OC designed the study and contributed in the data analysis. Aluh DO wrote the manuscript and participated in the data analysis. Both Authors critically revised and approved the final manuscript.

\section{ACKNOWLEDGEMENT}

We are grateful to all the Pharmacists surveyed in this study for their willingness to participate.

\section{CONFLICT OF INTERESTS}

\section{We declare no conflict of interest}

\section{REFERENCES}

1. Helper C, Strand M. Opportunities and responsibilities in pharmaceutical care. Am J Hosp Pharm 1990;47:3.

2. Ludwig Boltzmann. Institute for the sociology of health and medicine. health promotion in general practice and community pharmacy-conclusions and proposals from a European Project; 2002.
3. Malik M, Kanwal N, Hussain A. Role of community pharmacist and nutritionist in obesity management: a literature review. Asian J Pharm Clin Res 2017;10:40-2.

4. Keban S, Abdillah S, Najuah N. The role of pharmacists in evaluating and intervening the patients with diabetic neuropathy. Asian J Pharm Clin Res 2017;10:127-31.

5. Maria C, Vladimir S, Ala C, Nina S. An assessment of community pharmacists' attitudes towards professional practice in the republic of Moldova. Pharm Pract 2008;6:1-8.

6. Hanafi S, Somayeh H. Evaluation of community pharmacists' knowledge, attitude and practice towards good pharmacy practice in Iran. J Phys Chem 2013;1:19-24.

7. Villako P, Raal A. A survey of Estonian consumer expectations from the pharmacy service and a comparison with the opinions of pharmacists. Pharm World Sci 2007;29:546-50.

8. Pharmacist's council of Nigeria. Four-part compendium of minimum standards of pharmaceutical care in Nigeria, Abuja; 2005.

9. Pharmacists council of Nigeria. Pharmacy practice-code of ethics; 2015. Available from: http://www.pcn.gov.ng. [Last accessed on 15 Nov 2015].

10. Pharmacists council of Nigeria. Brief history; 2016. Available from: http://www.pcn.gov.ng/webpages.php?cmd=Nandpages $=2$ andmt $=$ Registryandsmt $=$ Brief\%20History. [Last accessed on 25 Sep 2016].

11. Yamane, Taro. Statistics: An Introductory Analysis. $2^{\text {nd }}$ Ed. New York: Harper and Row; 1967.

12. Puspitasari H, Aslani P, KrassI. A review of counselling practices on prescription medicines in community pharmacies. Res Social Adm Pharm 2009;5:197-210.

13. Kirking D. Pharmacists' perceptions of their patient counselling activities. Contemp Pharm Pract 1981;5:230-8.

14. Schnipper J, Kirwin L, Cotugno C, Wahlstrom A, Brown A, Tarvin E, et al. Role of pharmacist counselling in preventing adverse drug events after hospitalization. Arch Intern Med 2006;166:565-71.

15. Azhar H, Mohamed I. Perceptions of dispensers regarding dispensing practices in Pakistan: a qualitative study. Trop J Pharm Res 2011;10:117-23.

16. Gokcekus L, Toklu Z, Demirdamar R, Gumusel B. Dispensing practice in the community pharmacies in the Turkish Republic of Northern Cyprus. Int J Clin Pharm 2012;34:312-24.

17. Sinaa A, Norah 0 . Counselling practices in community pharmacies in Riyadh, Saudi Arabia: a cross-sectional study. BMC Health Serv Res 2015;15:557.

18. Ansari J. Drug interaction and pharmacist. J Young Pharm 2010;2:326-31.

19. Dameh M, Norris P, Green J. New Zealand pharmacists' experiences, practices and views regarding antibiotic use without a prescription. J Prim Health Care 2012;4:131-40.

20. Erah PO, Nwazuoke JC. Identification of standards for pharmaceutical care in benin city. Trop J Pharm Res 2002;1:55-67.

21. Oparah A, Eferakeya A. Attitudes of nigerian pharmacists towards pharmaceutical care. Pharm World sci 2005; 27:208-14.

22. The Royal Pharmaceutical society of Great Britain guidance on recording interventions; 2006.

23. Currie J, Doucette R, Kuhle J, Sobotka J. Identification of essential elements In the documentation of pharmacistprovided care. J Am Pharm Assoc 2003;43:41-7.

24. World Health Organization. Joint FIP/WHO guidelines on good pharmacy practice: standards for quality of pharmacy services. WHO Technical Report Series, No. 961. Geneva; 2011.

25. WHO Technical Report Series, No. 717. Health manpower requirements for the achievement of health for all by the year through primary health care: Report of a WHO Expert Committee; 2000.

26. AneGedde D, Pernille H, Hanne S, Marit B, Gerd G, Anne M. Characteristics and quality of adverse drug reaction reports by pharmacists in Norway. Pharmacoepidemiol Drug Saf 2007;16:9.

27. Salim M, Hussain N, Balasubramanian T, Lubab M, Nayana S. The current perspective of community pharmacists towards pharmacovigilance. J Pharmacovigil 2015;3:180. 
28. Mahmoud M, Alswaida Y, Alshammari T, Khan M, Alrasheedy A Hassali A. Community pharmacists' knowledge, behaviours and experiences about adverse drug reaction reporting in Saudi Arabia. Saudi Pharm J 2014;22:411-8.

29. Mahendra J, Sandeep A, Soumya M. A survey on assessing the knowledge, attitude and behaviour of community pharmacists to adverse drug reaction related aspects. Indian J Pharm Sci 2012;5:51-5.

30. Kulkarni G, Patil L. Analysis of adverse drug reactions spontaneously reported to adverse drug monitoring centre of a tertiary care hospital- a prospective study. Int J Curr Pharm Res 2018;10:23-5. 